\title{
CFD SIMULATION OF SINGLE STAGE AXIAL FLOW COMPRESSOR FOR VARYING BLADE ASPECT RATIO
}

\author{
Kumbhar Anil $\mathbf{H}^{1}$, Aashish Agarwal ${ }^{2}$ \\ ${ }^{1} P G$ Student, ${ }^{2}$ Associate Professor, Technocrats Institute of Technology, Bhopal, M.P, India, \\ anil2929@gmail.com,er_ashishagarwal@yahoo.com
}

\begin{abstract}
The aspect ratio of blade is an important parameter and has a strong influence on the performance of axial flow compressor. The performance of axial flow compressors is known to be affected by the choice of aspect ratio (the ratio of blade height to axial chord length). A study has been carried out to verify the effect of aspect ratio on the performance of 1.2 pressure ratio single stage subsonic compressor through AxStream analysis using Axial flow compressor design. The analysis has been carried out for the constant tip diameter of the compressor rotor blade having an aspect ratio 1, 2 and 3 and obtained the pressure loss and flow parameters of the compressor stage. This paper shows that the best operating conditions occur for the aspect ratio between 2 and 3.
\end{abstract}

Keywords: Axial flow compressor, Aspect ratio, Computational Fluid Dynamic, AxStream

\section{INTRODUCTION}

In the recent decades the axial flow compressor is an important part of any efficient gas turbine. An axial-flow compressor its working fluid by first accelerating the fluid and then diffusing it to obtain a pressure increase. The fluid is accelerating by a row of rotating airfoils or blades (rotor) and diffused by a stationary blade (stator). The diffusion in the stator converts the velocity gained in the rotor to a pressure rise. one rotor and one stator make up a stage in a compressor. One additional row of fixed blades (inlet guide vane) is frequently used at compressor inlet to insure that air enters the first-stage rotor at desired angle. Compressor efficiency is very important in the overall performance of the gas turbine as it consume $55-60 \%$ of the power generated by gas turbine. The industrial pressure ratio is low for reason that the operating range needs to be large. The operating range is the range between the surge point and chock point

Now a day research and developmental efforts in the area of axial flow compressors for gas turbine application are aimed to improving its operating range without sacrificing efficiency. An increase in aspect ratio (the ratio of blade height to chord length) has been observed to have an adverse effect on the performance of single-stage axial flow compressors.

In experimental, numerical and theoretical investigations have been performed in the past, studying the effects of aspect ratio on compressor performance, but yielded mixed results Meherwan P. Boyce [2003],G.J. Fohmi[1971], J.H. Horlock [1967], Ronuld J. Steinke und James E. Crozcse [1967], observed a Effects of Aspect Ratio on blade loading, blade excitation, and the pre-twist blade angles. At high aspect ratios the blades had to be designed with mid span shrouds, and tip shrouds. This decreases the efficiency of the stage; however, without the shrouds the pre-twist blade angle had to be increased and the blade excitation resulted in blade failure. Ronuld J. Steinke und James E. Crozcse study under the Lewis Research Center Cleveland, Ohio. Results of their studies do not indicate any basic limit on aspect ratio other than possible supersonic meridional velocities for acceptable design point performance. they note that off-design performance and mechanical design problems may limit the maximum usable aspect ratio. The high axial pressure gradients associated with higher aspect ratio blading could require refinements in the profile loss correlation that was used in order to predict performance accurately.

This paper describes the effect of aspect ratio by using 3Dimensional Computational Fluid Dynamics(CFD) commercial code AxStream to investigate the influence of aspect ratio on a single stage subsonic axial flow compressor. The objective of this paper is CFD analysis of single stage subsonic axial flow compressor at various aspect ratio (AR) configurations such as 1,2 and 3 to obtain the pressure loss and flow parameters to find best operating range of aspect ratio.

\section{DESCRIPTION OF THE COMPRESSOR}

In this paper various flow parameters and pressure loss are calculated for single stage axial flow compressor by considering different blade aspect ratios 1,2 and 3 . The objectives of this paper are to evaluate the effect of aspectratio curvature variations and radial distributions of pressure loss on flow parameters such as meridional velocity, Mach 
number and to determine whether any basic limit of aspect ratio exists in order to maintain acceptable design point performance between range of aspect ratio 1,2 and 3. The single stage axial flow compressor having inlet guide vane, Rotor \& stator is considering with constant tip diameter of pressure ratio 1.2.

\subsection{Main specification of axial flow compressor:}

Type of compressor: Single Stage Axial Flow compressor Working fluid : Ideal Gas

Corrected rotational speed: $14800 \mathrm{rpm}$

Corrected mass flow rate : $15.5 \mathrm{~kg} / \mathrm{s}$

Inlet pressure $\quad: 101.3250 \mathrm{Kpa}$

Stage total pressure ratio : 1.21

\section{METHODOLOGY}

The single stage axial flow compressor having inlet guide vane, rotor and stator are design for the operating range specified above with constant tip diameter in preliminary design mode. The preliminary design mode will give the outline of the compressor with inlet and outlet parameters. Initial data for the design are Preliminary design solution.

\subsection{Preliminary Design}

The design process starts with preliminary design procedure. It gives wide range of results to rapidly select optimal main flow path parameters, such as the number of stages, geometrical dimensions and angles, heat drop distributions etc. Preliminary design procedure performs calculation i.e. based on boundary conditions and calculates flow path geometry. After the calculation is finished its Calculation results will show on map.

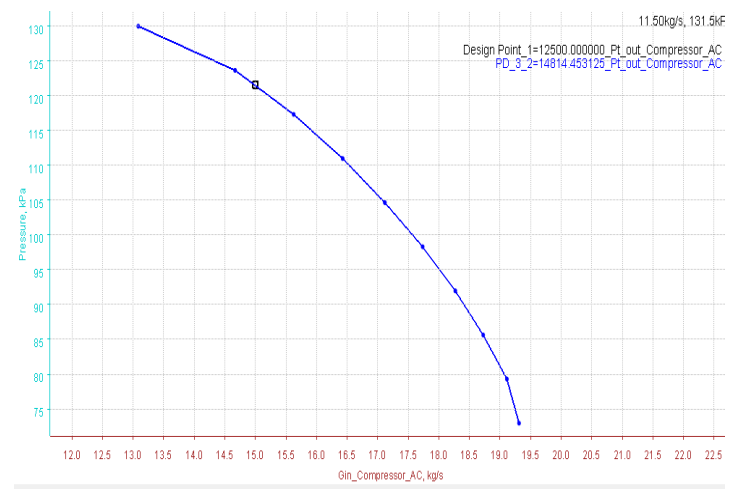

Fig.1 Pressure variation with mass flow rate

\subsection{Post Design and Streamline Calculations}

In this mode we are able to change aspect ratio of given compressor and run the streamline calculations. The paper will illustrate the aspect ratio variation only for the rotor. First select the rotor aspect ratio one and run the program it will give the result for aspect ratio one, and run the further calculations by changing aspect ratio 2 and 3. The result with aspect ratio 1,2 and 3 will show the various flow parameters i.e. static pressure distribution in compressor, total pressure and absolute pre distribution, meridonal velocity and mach no. is shown in fig. 2. The meridonal velocity is also shown in fig. 2 that will be vary through the compressor, maximum velocity is in the potion of IGV and rotor interaction gap and minimum at the inlet of the IGV of the given compressor.
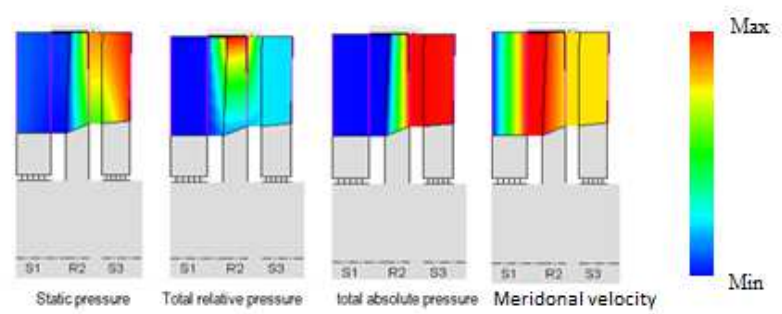

Fig.2 pressure and velocity distribution

The fig. 2 is indicating that the static pressure is maximum at the stator outlet of the compressor and minimum at the inlet guide vane inlet of compressor. The maximum relative pressure is at the inlet of the rotor and minimum at the inlet of inlet guide vane of compressor, similarly total absolute pressure is at the stator outlet of the compressor and minimum at the inlet guide vane inlet of compressor.

The mach number is vary thought the compressor fig. 3 shows that the relative mach number is maximum at the inlet of rotor which is indicate the high velocity at the inlet of rotor and minimum at the inlet of IGV and the stator outlet which is indicate the low velocity at the entrance and exit of the axial flow compressor.

$$
M=\begin{array}{ll}
v & M \text { is the Mach number, } \\
a & v \text { is the velocity of the source relative to the medium and } \\
a \text { is the speed of sound in the medium. }
\end{array}
$$
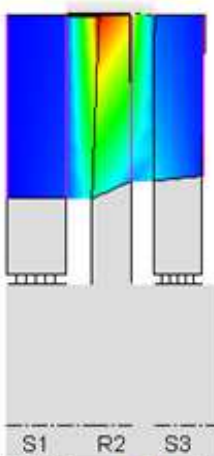

Relative mach number
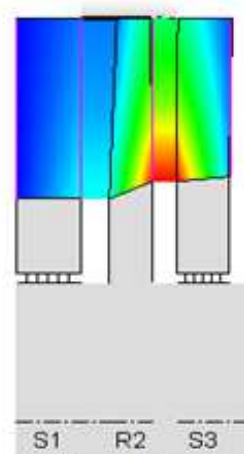

absolute mach number

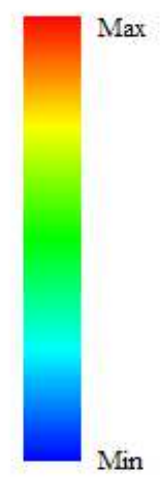

Fig.3 Mach number 
The major problem in compressor tuning is to choose proper criteria to estimate the effects of applying stators restaggering and bleeding. In a scope of current study the equivalent diffusion factor introduced by Lieblien. Equivalent diffusion factor introduced by Lieblien is

$$
\mathrm{Deq}=\frac{\mathrm{Wmax}}{\mathrm{W} 1} \frac{\mathrm{W} 1}{\mathrm{~W} 2}=\frac{\mathrm{Wmax}}{\mathrm{W} 1} \frac{\cos \beta 2}{\cos \beta 1} \frac{\mathrm{Wm} 1}{\mathrm{Wm} 2}
$$

Where,

$\mathrm{W}$ - Relative velocity Beta - Blade angle

1/2 -Inlet/Outlet station m- Meridional component

\subsection{D Blade Design and Modal Analysis}

The next step of is to perform profiling on plain profiles section to obtain optimal flow characteristics and pressure distributions. On the next step 3D blade design, stacking and shaping are performed, and complete geometry ready to export is obtained. In this section we adjust the curve of blade make the curvature of blade smooth to get the optimum result. This task is performed by blade parameter editing command i.e. Edit mode. The fig. 4 will show smooth curve of blade, After completing blade editing $2 \mathrm{D}$ calculation is run to get the $2 \mathrm{D}$ result.

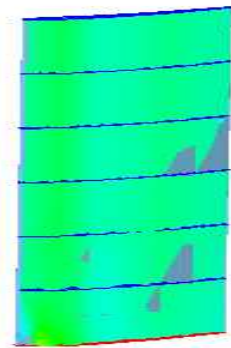

Fig.4 Blade profile

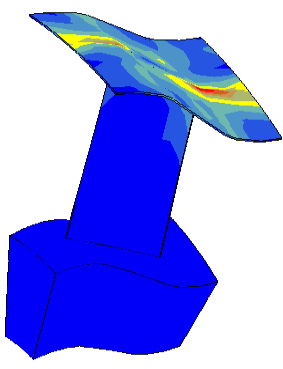

Fig.5 Modal analysis
3D structural and modal analysis will carried out for performing analysis. Modal analysis will give the frequency at various mode shown in fig. 5.This mode also shows the assembly of the IGV, rotor and stator for detail study of at various modes of frequency. The next mode of study will give the final result of the compressor with various flow parameters.

\subsection{Flow Analysis}

To evaluate designed blades in 3D CFD, AxCFD is used into AxSTREAM as express flow analysis with automatic meshgeneration. Results are display on screen as per selected mode of parameter. The fig. 6 is shows the variation of static pressure with different blade aspect ratio. The result will vary with aspect ratio, the static pressure is increase with increasing aspect ratio. The results are indicate that maximum pressure at aspect 1,2 and 3 are $158.6 \mathrm{kpa}, 195.1 \mathrm{kpa}$ and $159.6 \mathrm{kpa}$ is shown in fig. 6 .

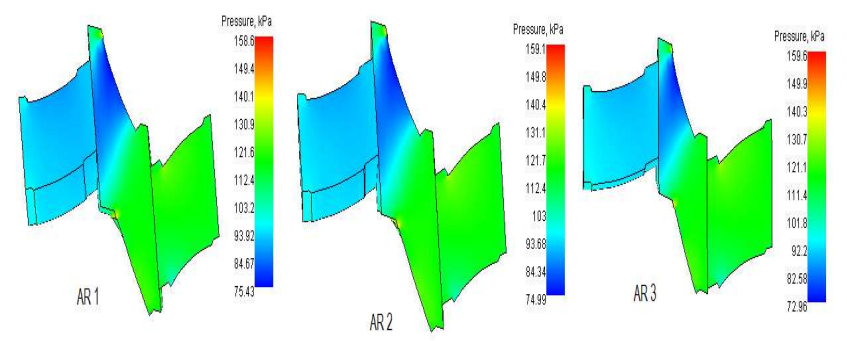

Fig.6 Static pressure

The total absolute pressure and relative pressure is shown in fig. 7 and 8 that will also increased with increasing aspect ratio. Results are shows that maximum total absolute pressure at $\mathrm{AR} 1,2$ and 3 are $236.2 \mathrm{kpa}, 237.1 \mathrm{kpa}$ and $239.7 \mathrm{kpa}$ respectively.

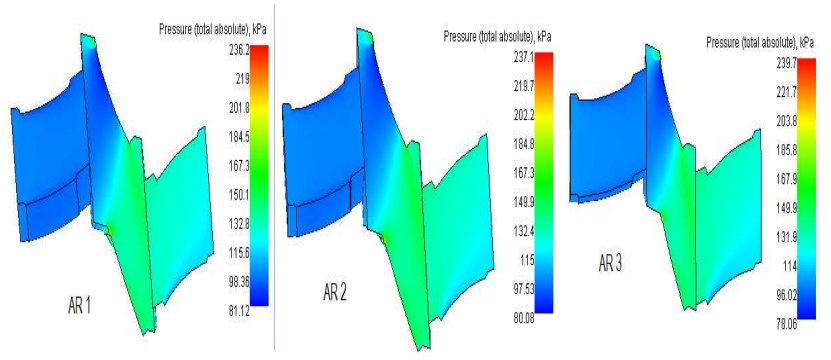

Fig.7 Total absolute pressure

Total relative pressure are is variation are little change as compare to the static pressure and total absolute pressure, the maximum pressure is achieved by considering aspect ratio these aspect ratio are $174.9 \mathrm{kpa}, 175.3 \mathrm{kpa}$ and $173.2 \mathrm{kpa}$. These result indicate that maximum pressure achieved in aspect ratio 2 then slightly less in aspect ratio 1 and minimum is at the aspect ratio 1 . This result is shows that aspect ratio 2 will give maximum total relative pressure as compare to aspect ratio 1 and 3 shown in fig. 8 .

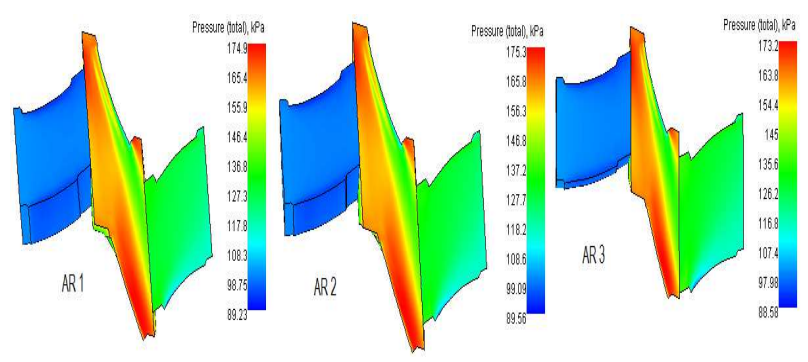

Fig.8 Total relative pressure 
The maximum maridonal velocity is $165.4 \mathrm{~m} / \mathrm{s}$ in third case then continuously decrease with decreasing aspect ratio are $162.7 \mathrm{~m} / \mathrm{s}$ and $162.2 \mathrm{~m} / \mathrm{s}$ shown in fig. 9

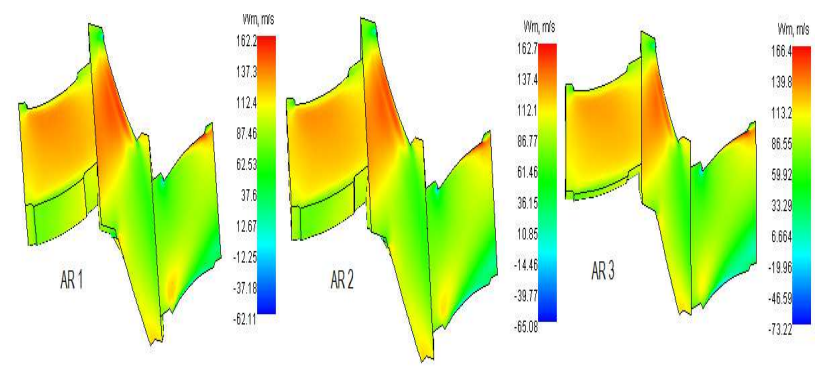

Fig.9 Meridonal velocity

The mach number is important parameter in compressor, the absolute mach number is also increased with increasing aspect ratio shown in fig. 10

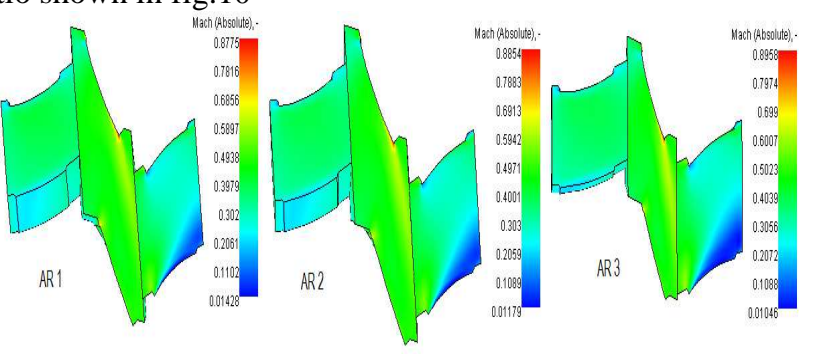

Fig.10 Absolute Mach number

The Relative Mach number is also increased with increasing aspect ratio shown in fig. 10 . The maximum mach number is at the inlet of the rotor which is 1.081 that is illustrate the velocity is maximum at the rotor inlet, the minimum mach number at the outlet of the stator that shows the velocity is decrease in that section and pressure is increase.

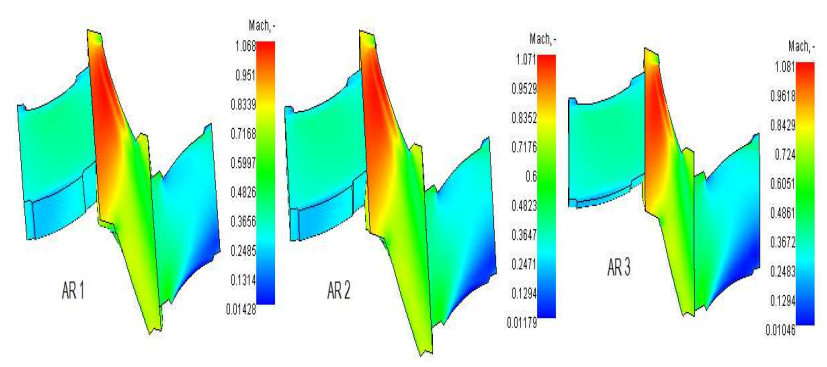

Fig.11 Relative Mach number

The result of axial flow compressor is also compare with the varying aspect ratio from 1 to 3 are in the chart below. The CFD package will give the facility compare the result at various section in the axial flow compressor.

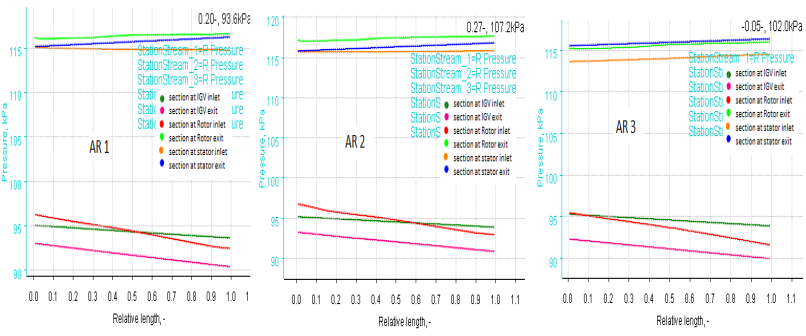

Fig.12 Static pressure
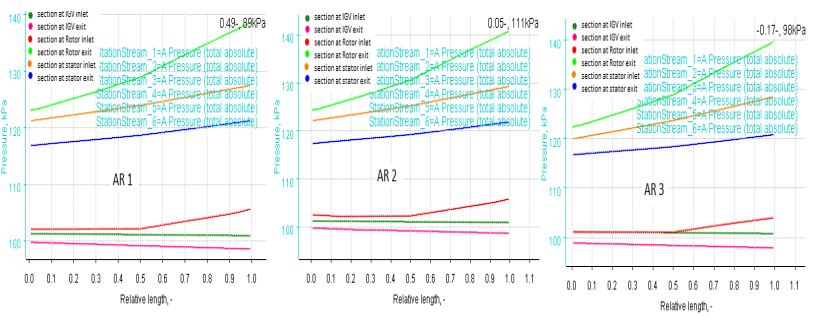

Fig.13 Total absolute pressure
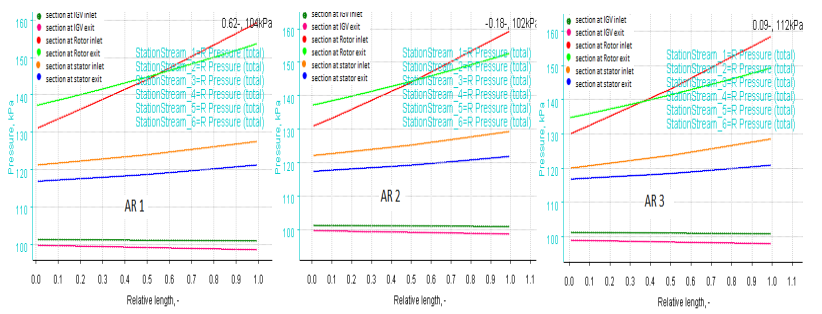

Fig.14 Total relative pressure

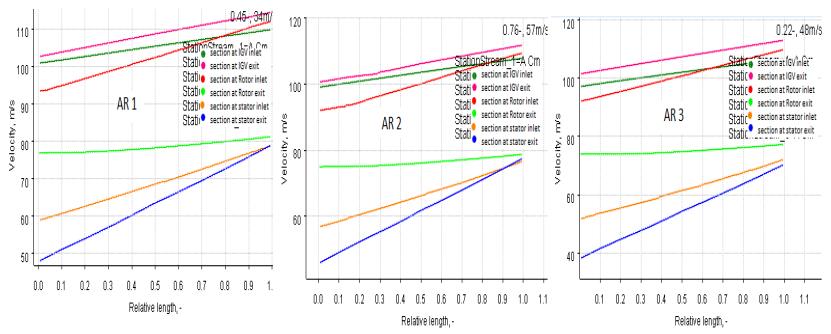

Fig.15 Meridonal velocity

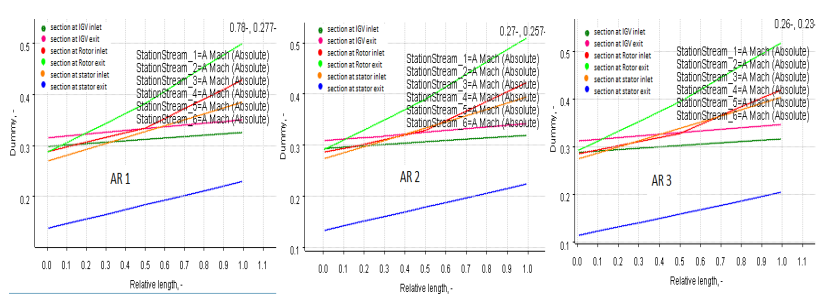

Fig.16 Absolute Mach number 

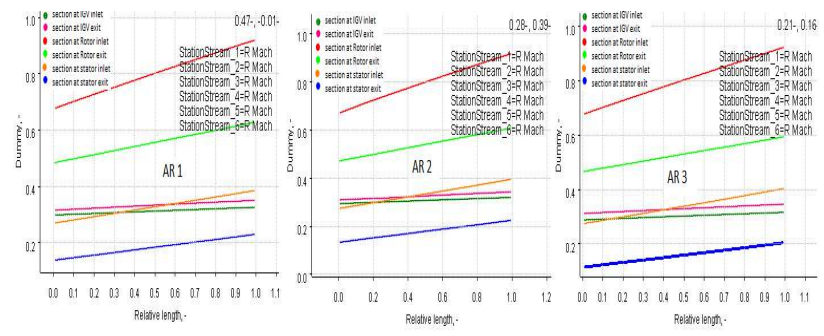

The result shown in the graphs are the distribution of various flow parameters of axial flow compressor at the various sections. The sections are created at the entrance and exit of inlet guide vane, rotor and stator. Also the result display in the chart with various flow parameters.

Fig.17 Relative Mach number

\subsection{Results}

\begin{tabular}{|c|c|c|c|c|c|}
\hline Sr No. & Property & Unit & AR 1 & AR 2 & AR3 \\
\hline 01 & Stat. Pressure At Outlet & Kра & 113.7122 & 114.174756 & 114.165971 \\
\hline 02 & Total Pressure At Outlet & $\mathrm{Kpa}$ & 121.5935 & 121.593498 & 121.637599 \\
\hline 03 & Power & KW & 270.6084 & 261.047898 & 262.802038 \\
\hline 04 & Total Efficiency & - & 0.901984 & 0.902032 & 0.901957 \\
\hline 05 & Polytropic Efficiency & - & 0.903580 & 0.903683 & 0.903608 \\
\hline 06 & Total-Static Pressure Ratio & - & 1.122253 & 1.126817 & 1.126731 \\
\hline 07 & Diffusion Factor(By Nasa) & & 0.285267 & 0.284491 & 0.283775 \\
\hline 08 & Diffusion Factor By De Haller & & 0.826342 & 0.823076 & 0.823087 \\
\hline 09 & Average Flow Coefficient & & 0.3328 & 0.336 & 0.3382 \\
\hline 10 & Total Pressure Rise & Kpa & 20.26850 & 20.26849 & 20.312599 \\
\hline 11 & Total Pressure Loss Factor & & 0.03229 & 0.045350 & 0.046292 \\
\hline 12 & Profile Pressure Loss Factor & & 0.016394 & 0.022687 & 0.023610 \\
\hline
\end{tabular}

\section{CONCLUSIONS}

In this paper the computational fluid dynamic analysis has been carried out by varying AR 1, 2 and 3 on a single stage subsonic axial flow compressor of 1.2 pressure ratio to obtain the overall performance of the compressor using commercial code AxStream. The result shows that power consumption decrease in AR 2, Total efficiency is increased in AR2. It is also indicate that with increasing AR the diffusion factor (by NASA) is decrease and diffusion factor by de Haller is slightly decrease in AR2. Total pressure rise is increased with increasing $\mathrm{AR}$, furthermore total pressure loss factor and profile loss factor is also increased with increasing AR.

Through this paper, it has been clearly brought out that, the best aspect ratio for the referred single stage axial flow compressor is in between 2 and 3. The computational results should be validate by performing experimental work under controlled conditions.

Hence future work will be to do the analysis taking aspect ratios in more discrete manner i.e. 2, 2.2, 2.4, 2.6, 2.8, 3 in this way we can get optimum aspect ratio.

\section{REFERENCES}

[1] Boyce, M.P. 2003. Gas Turbine Engineering Handbook, Second Edition, Butterworth- Heinemann

[2] Werner R. Britsch, Walter M. Osborn and Mark R. Laessig. 1979. Effects of Diffusion Factor, Aspect Ratio, and Solidity on Overall Performance of 14 Compressor Middle Stages. NASA Technical Paper 15230

[3] Hanoca P, Shobhavathy M T. 2011.CFD analysis to investigate the effect of axial spacing in a single stage transonic axial flow compressor. Symposium on Applied 
Aerodynamics and Design of Aerospace Vehicle (SAROD 2011) November 16-18, Bangalore, India.

[4] Ronuld J. Steinke und James E. Crozcse. 1967. Analytical studies of aspect ratio and curvature variation for axial flow compressor-inlet stages under high loading. national aeronautics and space administration Washington, d. c. may.

[5] G.T.S. Fahmi. 1967.The performance of axial flow compressor of different blade aspect ratio. London: her majesty's stationary office.

[6] J. H. Horlock and G J. Fahmi. 1967. A Theoretical Investigation of the Effect of Aspect Ratio on Axial Flow Compressor Performance. London: her majesty's stationary office.

[7] Herrig, L.J., Emery, J.C., and Erwin, J.R. 1955. Systematic Two Dimensional Cascade Tests of NACA 65 Series Compressor Blades at Low Speed. NACA R.M. E $55 \mathrm{H} 11$.

[8] Axial flow compressor design, Turbomachinery Flow Path Conceptual Design Suite, AxSTREAM.

[9] HIH Saravanamuttoo, GFC Roger and Hcohen, "Gas Turbine Theory" 5 th Edition, PEARSON Education. 